\title{
VENTRICULOPERITONEAL SHUNT INFECTIONS
}

\author{
P Sarguna, *V Lakshmi
}

\begin{abstract}
Central nervous system (CNS) shunt infection is a cause of significant morbidity, causing shunt malfunction and chronic ill health. This study was carried out to evaluate the infection rate associated with CNS shunts, assess the frequency of the pathogens as well as their antibiotic sensitivity pattern aiming at suitable prophylaxis. A retrospective analysis of 226 CSF cerebrospinal fluid (CSF) shunt procedures sent for bacteriological work up over a period of one year and six months was undertaken. Laboratory diagnosis was established by subjecting the CSF to cell count, biochemical tests, bacteriological culture and antibiotic susceptibility test. Nine out of 226 (3.98\%) of the CSF samples were culture positive. Coagulase negative Staphylococcus was the most common isolate accounting for $36.36 \%$. Majority of the isolates were sensitive to the thirdgeneration cephalosporins and quinolones. The antibiotic sensitivity pattern suggests cephalosporins and quinolones to be a better choice of antibiotics either prophylactically or therapeutically, which may result in effective and rapid sterilisation of the CSF.
\end{abstract}

Key words: Cerebrospinal fluid shunts, shunt colonization, coagulase negative Staphylococcus, Gram negative bacteria

Ventriculoperitoneal (VP) shunt is one of the commonest procedures in neurosurgical practice. A significant problem encountered in shunt procedures is infection, with infection rate ranging from 2 to $27 \%$, often with poor outcome. ${ }^{1-6}$ Shunt associated infections are most frequently $(65 \%)$ caused by coagulase negative Staphylococcus (CoNS). ${ }^{5,7,8}$ Gram negative bacteria are the next most frequent pathogens, accounting for $19 \%$ to $22 \%$ of cases. ${ }^{5,9}$

We undertook a retrospective analysis of all the cases of shunt infections over a period of one year and six months. The objectives of the study were to evaluate the infection rate associated with central nervous system (CNS) shunts, assess the frequency of the pathogens as well as their antibiotic sensitivity pattern to aim at suitable prophylaxis.

\section{Materials and Methods}

Two hundred and twenty-six cerebro spinal fluid (CSF) shunt related procedures performed at Nizam's Institute of Medical Sciences (NIMS), Hyderabad, over a period of one year and six months were included in the study. The relevant data included, the age of the patient, the clinical condition requiring shunt procedure, laboratory data, antibiotic prophylaxis, therapy and follow up of the patients. The samples comprised of ventricular fluid, shunt tube, reservoir and blood for culture. The samples were processed using standard bacteriological procedures and the antibiotic susceptibility of the isolates was determined. ${ }^{10}$

*Corresponding author (email: <lgorthi@hotmail.com>)

Department of Microbiology, Nizam's Institute of Medical Sciences, Hyderabad - 500 082, Andhra Pradesh, India

Received: 06-04-05

Accepted: 10-10-05

\section{Results}

During the study period, nine shunt infections resulted from 226 shunt procedures, giving an overall infection rate of $3.98 \%$.Of the nine patients who got infected, there were seven males and two females. Six of the males and one female were below 15 years of age. Underlying condition in the above infected cases were congenital malformations in four patients, residual craniopharyngioma in one patient, astrocytoma in one patient, tuberculous meningitis with hydrocephalus in one patient and syringomyelia with syringobulbia in one patient.

Of the nine infections, six occurred within 30 days of the most recent shunt procedure, which was either the primary shunt operation or procedure to revise the shunt. Late infections occurred in three cases, about three months, seven months and two years after shunt revision, respectively. However, no deaths occurred as a result of shunt infection.

Shunt infection was defined as isolation of the organism from the ventricular fluid, shunt tube, reservoir, and/or blood culture along with the clinical signs and symptoms suggestive of shunt infection or malfunction like fever, peritonitis, meningitis, signs of infection along the shunt tract, or nonspecific signs and symptoms of headache, vomiting, change in mental status, or seizures. Fever (44.44\%) and vomiting $(33.33 \%)$ were the most common clinical symptoms. Altered sensorium, abdominal tenderness and seizures were less common manifestations.

In all cases the CSF was clear and revealed no pleocytosis and no fall in the glucose levels. All CSF and blood cultures were sterile. Eleven bacterial isolates were recovered from the VP shunt tubes Eight infections were due to single organism, while in one case multiple isolates of CoNS, Pseudomonas 
aeruginosa and $E$. coli were encountered. The number of isolates in all was Coagulase negative Staphylococcus (CoNS) -Pseudomonas aeruginosa (3), E. coli (3) and Klebsiella pneumoniae (1).

All the patients had undergone the shunt procedure under prophylactic antibiotic cover with the combination of ampiclox, gentamicin or ceftriaxone. Majority of the isolates were sensitive to amikacin, third generation cephalosporins especially ceftriaxone and ciprofloxacin. All the patients survived after the infected shunts were removed.

\section{Discussion}

The eradication of infection in patients with colonized shunts has always been a great challenge to the treating surgeon. Various methods have been tried with variable success. Meticulous asepsis preoperatively and intraoperatively is essential in preventing colonization. ${ }^{7}$ Infections following VP shunt procedure are secondary to catheter blockage complicating the results of surgery and are associated with high morbidity and mortality rates. ${ }^{1}$ Colonized shunts do not function well mechanically. ${ }^{11}$ However, no deaths occurred as a result of shunt infection in our series.

Majority of infections occur within one to two months of surgery. ${ }^{12,13}$ In all the nine cases, the organisms were isolated solely from the shunt tube, indicating an early colonization. There was no spread of infection to the CSF or to the blood stream. ${ }^{14}$ Although positive CSF culture might be expected to be the final arbiter of the presence or absence of infection in a shunt in situ, cultures may be negative even when the shunt devise harbours infection. ${ }^{14-16}$ In such circumstances it could be an indolent infection with colonization of shunt and a sterile CSF. ${ }^{15,16}$

Coagulase negative Staphylococcus was the most frequent isolate encountered in our series. In gram positive shunt infections, majority of the organisms are commensals of the skin, a result of direct wound contamination during surgery. ${ }^{12}$ Although gram negative bacterial colonization of the skin is not common, they could probably be introduced during surgery. Another probable mechanism is 'retrograde' infection, in which an asymptomatic perforation of the bowel leads to distal contamination of the VP shunt catheter and retrograde progression of infection. ${ }^{13,17}$ The sources of infection in colonized shunts showed that in majority of cases the causative organism was present at the operative site prior to and during surgery. ${ }^{12}$

Aminoglycosides and penicillin group of drugs were prophylactically administered in our study group. Though aminoglycosides prove effective in vitro, the poor in vivo response could be explained by the difficulty in achieving a consistent peak CSF concentration of the aminoglycosides exceeding the minimum inhibitory concentration (MIC) values of the pathogens. On the other hand, the peak CSF levels achieved with cephalosporins (ceftriaxone) is often more than 100 fold greater than MIC values of most of the pathogens. This results in an effective and rapid sterilisation of the csf with the latter group of drugs. ${ }^{13,18}$ Therefore, it is advisable to alter the prophylactic regimen to include third generation cephalosporins and a quinolone, which can achieve effective CSF levels.

The prophylactic and long term use of antibacterial agents $^{3,8}$ along with prompt removal of and replacement of the drainage system has provided the best results in shunt colonization. ${ }^{7,11}$ CSF shunt infections treated appropriately are not associated with excessive morbidity and mortality. Early infections discovered within 60 days of surgery are most likely to respond to medical management. ${ }^{19}$ Outcome of the patients is better if shunt infections are identified early and managed with appropriate antibiotics. Identifiying the risk factors and predictors of infectious agents may help prevent shunt infections.

\section{References}

1. Bhatnagar V, George J, Mitra DK, Upadhyaya P. Complications of cerebrospinal fluid shunts. Indian J Pediatr 1983;50:133-8.

2. Kaufman BA, Mc Lone DG. Infection of cerebrospinal fluid shunts, In: Infection of the central nervous system, Scheld WM, Whitley RJ, Durack DT (Editors). Raven press: New York; 1991. p. 561-85,

3. Morrice JJ, Young DG. Bacterial colonization of Holter valves; A Ten-year survey. Dev Med Child Neurol 1974;16:85-90.

4. Olsen L, Fryberg T. Complications in the treatment of hydrocephalus in children. Acta Pediatr Scand 1983;72:385-90.

5. Schoenbaum SC, Gardener P, Shillito J. Infections of the cerebrospinal fluid shunts; epidemiology, clinical manifestation and therapy. J Infect Dis 1975;131:543-52.

6. Sells CJ, Shurtleff DB, Loeser JD. Gram negative cerebrospinal fluid shunt associated infections. Pediatr 1977;59:614-8.

7. Bhatnagar V, Mitra DK, Upadhyaya P. Shunt related infections in hydrocephalic children. Indian Pediatr 1986;23;255-7.

8. Holt RJ. Bacteriological studies in colonized ventriculoatrial shunts. Dev Med Child Neurol 1970;12:83-7.

9. Ersahin Y, Mc Lone DJ, Storrs BB, Yogev R. Review of 3017 procedures for the management of hydrocephalus in children. Concepts Pediatr Neurosurg 1989;9;21-8.

10. Miles RS, Amyes SG. Laboratory control of antimicrobial therapy, Chapter 8. In: Mackie \& Mc Cartney Practical Medical Microbiology, $14^{\text {th }}$ edn. Collee JG, Fraser AG, Marmion BP, Simmons A, Editors. Churchill Livingstone: New York; 1996. p. $151-78$

11. Nicholas JL, Kamal IM, Eckstein HB. Immediate shunt replacement in the treatment of bacterial colonization of Holter valves. Dev Med Child Neurol 1970;22:110. 
12. Bayston R, Lari J. A study of sources of infection in colonized shunts. Dev Med Child Neurol 1974;16:16-22.

13. Stamos JK, Kaufman BA, Yogev R. Ventriculoperitoneal shunt infections with Gram negative bacteria. Neurosurgery 1983;33:858-62.

14. Palur R, Rajshekhar V, Chandy MJ, Joseph T, Abraham J. Shunt surgery for hydrocephalus in tuberculous meningitis: A longterm follow-up study. J Neurosurg 1991;74:64-9.

15. Rekate HL, Ruch T, Nulsen FE. Diphtheroid infections of cerebrospinal fluid shunts. The changing pattern of shunt infections in Cleveland. J Neurosurg 1980;52:553-6.

16. Walters BL, Hoffman JH, Henrick EB, Humphreys RP.
Cerebrospinal fluid shunt infections. Influences on initial management and subsequent outcome. J Neurosurg 1984;60:1014-21.

17. Rubin RC, Ghatak NR, Kisudhipan P. Asymptomatic perforated viscus and Gram-negative ventriculitis as a complication of valve regulated ventriculoperitoneal shunts. J Neurosurg $1972 ; 37 ; 616-8$.

18. Chadwick EG, Yogev R, Shulman ST, Weinfeld RE, Patel IH. Single-dose ceftriaxone pharmacokinetics in pediatric patients with central nervous system infections. $J$ pediatr 1983;102:1347.

19. Shapiro K, Shulman K. Shunt infections:A protocol for effective treatment. Monogr NeurSci s1882;8:69. 